\title{
A study on novel coupled membrane bioreactor with electro oxidation for biofouling reduction
}

\author{
Kamalakannan Vasanthapalaniappan ${ }^{1}$, Kavitha Palani ${ }^{1}$, Shanmuga Sundar Saravanabhavan ${ }^{1}$, \\ Narendranath Jonna1, Maharaja Pounsamy², Kannan Natarajan ${ }^{3}$, Yun Suk Huh ${ }^{4}$, \\ Balasubramanian Natesan ${ }^{1^{\dagger}}$ \\ ${ }^{1}$ Department of Chemical Engineering, A.C.Tech campus, Anna University, Chennai 25, India \\ ${ }^{2}$ CSIR - Central Leather Research Institute, Adyar, Chennai 20, India \\ ${ }^{3}$ Department of Biotechnology, Manipal Institute of Technology, Manipal, Karnataka-576104, India \\ ${ }^{4}$ Department of Biological Engineering, Biohybrid Systems Research Center (BSRC), Inha University, 22212, Republic of Korea
}

\begin{abstract}
The present study focuses on a novel method to integrate the electro-oxidation process with membrane bioreactor to reduce biofouling and increase the biodegradability index. Here, we used electro-oxidation as pretreatment with membrane bioreactor operating at a current density of $1.5 \mathrm{~mA} / \mathrm{cm} 2$ with hydraulic retention time at six h. The mixed liquor suspended solids concentration was maintained constant at $3,200 \mathrm{mg} / \mathrm{L}$ throughout the experiment for 30 days. The results obtained were promising with the percentage removal of COD, TOC, total nitrogen, and chlorides were in the range of $97 \%, 90 \%, 94 \%$, and $15 \%$, respectively, which was comparatively higher than the existing membrane bioreactor. The biodegradable index of treated water was higher, reaching a maximum of 0.6 , which is remarkably high compared with 0.3 in a membrane bioreactor. The integrated electro-oxidation process was efficient for the complete removal of pollutants from wastewater, which was confirmed using gas chromatography. In addition, the phytotoxicity test showed a significantly higher quality of treated water compared with that of raw tannery effluent. Hence, our proposed integrated electro-oxidation process can be used to decrease biofouling with increased biodegradability index as a replacement for MBR.
\end{abstract}

Keywords: Biofouling, Biodegradability Index, Electro-Oxidation, Membrane Bioreactor, Mineralization

\section{Introduction}

Water being one of the essential resources for the survival of living organisms on earth, has always been the topic of interest for researchers. The availability of fresh water in surface accounts only to $2 \%$, but industries such as the tannery, textile, distillery, dairy, pulp, and paper discharge their contagious wastewater into the surface water, which devastates water quality. This in turn, affects as well as destroys the activity of aquatic life prevailing in water. One of the main criteria in the preservation of wastewater from industries is to make treatment such a way it meets the discharge standards before getting discharged in water sources. Despite having so many drawbacks, the conventional treatment practices are still maintained by many industries, which in turn fail to treat the industrial effluent within the permissible limit. The other reason is due to the stringent nature and complexity of the discharged effluent quality and anthropogenic substances [1-4]. MBR has a smarter and wider recognition in the wastewater treatment process due to its high robustness and reliability [5]. The excellent feature in the MBR to emerge as a highly potential process [6] than the conventional water treatment process is a combination of activated sludge process (ASP) followed by a membrane as a filtration process $[1,7,8]$. MBR increases the efficacy of treatment process by concentrating the biomass [5] and increasing the quality of the outlet water which is very much superior to any other treatment process [9], one of the most notable advantages in the MBR process is its capacity to treat higher organic load sewage water [10, 11]. In spite of so many advantages, there exist one major limitation,
This is an Open Access article distributed under the terms of the Creative Commons Attribution Non-Commercial License (http://creativecommons.org/licenses/by-nc/3.0/) which permits unrestricted non-commercial use, distribution, and reproduction in any medium, provided the original work is properly cited.

Copyright (C) 2021 Korean Society of Environmental Engineers
Received January 24, 2020 Accepted September 02, 2020

${ }^{\dagger}$ Corresponding author

Email: nbsbala@gmail.com

Tel: 0442235 9190/9172

ORCID: 0000-0003-0763-8595 
i.e., fouling of the membrane, which can be noticed in the decline of permeate flux. The fouling of membrane occurs mainly due to a higher concentration of soluble microbial products (SMP), leading to the formation of cake layer over the membrane, subsequently resulting in pore blocking of the membrane [12-14]. To overcome the disadvantages in MBR, pretreatment prior to MBR is required. Advanced oxidation process such as photocatalysis [15], electro-oxidation, ozonation [16] and $\mathrm{UV} / \mathrm{H}_{2} \mathrm{O}_{2}$ provides a better and compromising solution for pretreatment of wastewater. Electro-oxidation (EO) process increases the biodegradability index (BI) by decomposing the complex compounds, thereby increasing the activity of biological treatment prevailing in the MBR to degrade pollutants. Electrolytes prevailing in the industrial effluent dissociate into ions, and oxidation occurs in the anode, aiding the degradation of organic pollutants, converting them to the inorganic substance without any secondary pollutants [17]. In the last decade, EO coupled to MBR found to be a topic of interest for many researchers, and the same has produced many interesting results. This system resulted in the reduction of fouling on the membrane and improved MBR performance [18, 19]. Borea et al. [19], reported that the maximum efficiency in fouling mitigation and application of electric filed on MBR. The study on submerged membrane electro-bioreactor (SMEBR) by Khalid et al., reported that the fouling rate was reduced up to $16.3 \%$ than $\mathrm{MBR}$ without any back-washing with an intermittent supply of electric field combined with membrane bioreactor [20]. Whereas, Ibeid et al. [21], demonstrated that the SMEBR system had a lesser membrane biofouling rate by increasing the removal rate of organic materials and soluble microbial products (SMP). In addition, when electrochemical oxidation used as a post-treatment showed a better removal efficiency than pretreatment configuration [22]. The coupled membrane bioreactor with electrochemical oxidation ( $\mathrm{PbO} 2$ as anode) as a post-treatment [23], showed a $99.9 \%$ removal of toxic pollutants (CBZ), in which electro-oxidation process plays a vital role towards the removal of toxic pollutant. From various research, it is clear that electro-oxidation (as pretreatment), when coupled with membrane bioreactor, will be effective towards the treatment of tannery wastewater, which is not reported to date. Another study showed a decrease in fouling rate by six times in the case of EO coupled MBR compared to normal MBR with a current density (CD) ranging between 15-35 $\mathrm{A} / \mathrm{m}^{2}$. [24]. The drawbacks of using EO and MBR individually, such as, the cost for membrane replacement, cleaning most importantly membrane fouling in MBRs are a concern, whereas in EO corrosion of electrode over time and passivation makes both the method to use individually [25, 26]. Hence, the present study focuses on combining MBR with an advanced oxidation process, resulting in a high potential process, and with the introduction of EO, the load on the membrane process gets reduced, resulting in a minimal fouling rate. This study has used tannery wastewater for the treatment process to which integrated EO pretreatment to MBR (IEOMBR) to increase the BI. Index and reduce biofouling on the membrane.

\section{Material and Methods}

\subsection{Experimental Setup for IEOMBR, MBR}

Treatment of tannery wastewater was carried out in a volume of $57 \mathrm{~L}$ pilot plant made up of acrylic material consisting of both activated sludge process followed by microfiltration process separated into two segments in a single reactor at ambient conditions and is represented as a schematic diagram in Fig. 1. The microfiltration membrane utilized in this process is composed of reinforced polyvinylidene fluoride (RPVDF), the pore size of the membrane is $0.22 \mu \mathrm{m}$. The spiral wound membrane module is used to carry out the entire experiments, and the filtration surface area is $0.5372 \mathrm{~m}^{2}$, three modules have been used in this work, and each module has 250 fibers. The membrane was procured from the local vendor Davey industries, Chennai, Tamil Nadu - 600053. The membrane unit is supported with a back-wash (for 60 seconds) unit along with the chemical dosage (sodium hypo chloride) at $60 \mathrm{~min}$ interval in the continuous process. The experiments were carried out in both batch mode to optimize the parameters for the EO process and in continuous mode for Integrated Electro-oxidation Membrane Bioreactor (IEOMBR) process. For EO process, titanium coated with ruthenium oxide/iridium oxide engaged as anode material and stainless steel as the cathode and the electrode material were purchased from the local Manufacturer TIFAB industries, Chennai Tamil Nadu - 600059. The anode and cathode electrode $\left(25^{\star} 17 \mathrm{~cm}\right)$ is stacked into a single cell to increase the process efficiency, and the distance between each electrode is $2 \mathrm{~cm}$; it is maintained constantly till the end of the experiment.

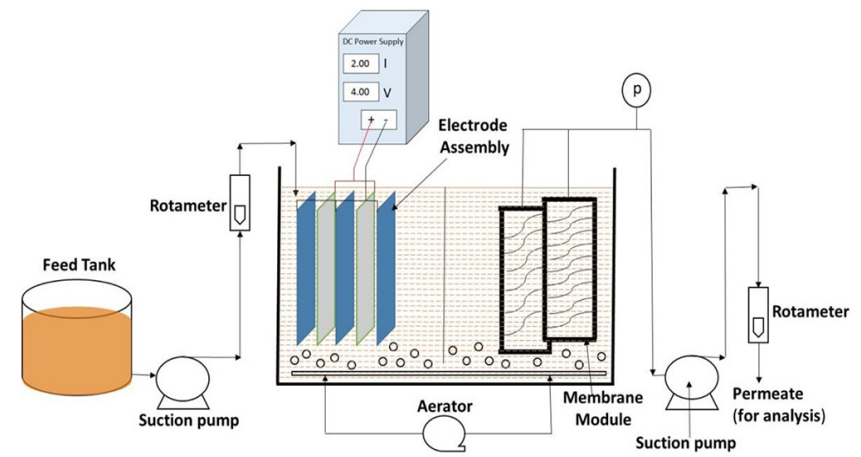

Fig. 1. Schematic representation of Integrated Electro-oxidation membrane bio-reactor.

\subsection{Collection of Sample}

The effluent sample was collected from the Common Effluent Treatment Plant (CETP), Chennai, Tamil Nadu, India, which is the second-largest plant to treat the tannery wastewater in Tamil Nadu. From the water collected, it was evident that there is an absence of heavy metal, chromium since the vegetable tanning process was carried in and around the plant. The activated sludge was also collected from the same operation plant.

\subsection{Analytical Methods}

\subsubsection{Physio-chemical characterization}

The samples collected were stored below $5^{0} \mathrm{C}$ for analysis, and physicochemical characterization was done, as mentioned in Table 1. All the analyses were done in triplicate. The treated samples were tested for Chemical Oxygen Demand (COD), Biological Oxygen Demand $\left(\mathrm{BOD}_{5}\right)$, Total Suspended Solids (TSS), Mixed Liquor Suspended Solids (MLSS) based on American Public Health 
Table 1. Characteristics of the Tannery Wastewater Used before and after Treatment with EO, MBR and IEOMBR, Respectively

\begin{tabular}{|c|c|c|c|c|c|c|}
\hline S. No. & Parameter & Before Treatment & EO Results & MBR Treated Water & IEOMBR Treated Water & TNPCB Norms \\
\hline 1 & Color & Brown & Colorless & Mild Brown & Colorless & Colorless \\
\hline 2 & $\mathrm{pH}$ & 6.9 & 7.0 & 7.0 & 7.0 & $5.5-9.0$ \\
\hline 3 & Chemical Oxygen Demand (COD) & $4,800 \mathrm{mg} \mathrm{O}_{2} / \mathrm{L}$ & $864 \mathrm{mg} \mathrm{O} / \mathrm{L}$ & $1,800 \mathrm{mg} \mathrm{O}_{2} / \mathrm{L}$ & $192 \mathrm{mg} \mathrm{O} / \mathrm{L}$ & $250 \mathrm{mg} \mathrm{O} / \mathrm{L}$ \\
\hline 4 & Biological Oxygen Demand (BOD) & $1,100 \mathrm{mg} \mathrm{O} / \mathrm{L}$ & $250 \mathrm{mg} \mathrm{O} / \mathrm{L}$ & $300 \mathrm{mg} \mathrm{O} / \mathrm{L}$ & $27 \mathrm{mg} \mathrm{O}_{2} / \mathrm{L}$ & $50 \mathrm{mg} \mathrm{O}_{2} / \mathrm{L}$ \\
\hline 5 & Total Organic Carbon (TOC) & 734.9 mg/L & $154.32 \mathrm{mg} / \mathrm{L}$ & $152 \mathrm{mg} / \mathrm{L}$ & $59.88 \mathrm{mg} / \mathrm{L}$ & NA \\
\hline 6 & Total Nitrogen (TN) & $140.8 \mathrm{mg} / \mathrm{L}$ & $35 \mathrm{mg} / \mathrm{L}$ & $41 \mathrm{mg} / \mathrm{L}$ & $7.83 \mathrm{mg} / \mathrm{L}$ & $50 \mathrm{mg} / \mathrm{L}$ \\
\hline 7 & Total Chloride & $1,278 \mathrm{mg} \mathrm{Cl} / \mathrm{L}$ & $1,125 \mathrm{mg} \mathrm{Cl} / \mathrm{L}$ & $1,150 \mathrm{mg} \mathrm{Cl} / \mathrm{L}$ & 1,050mg Cl/L & $1,000 \mathrm{mg} \mathrm{Cl} / \mathrm{L}$ \\
\hline
\end{tabular}

Association Standards, APHA [27].

\subsection{Analytical Methods}

2.4.1. Total organic carbon and total nitrogen analysis

The Total Organic Carbon (TOC) and Total Nitrogen (TN) were analyzed by using TOC-TN Analyser (SHIMADZU Model No: SHIMADZU CORP 00291, India). The TOC analysis were carried out to ensure the conversion of organic pollutant to carbon dioxide and water.

\subsubsection{Scanning electron microscope}

The surface of the membranes before and after treatment was analyzed using a scanning electron microscope (SEM HITACHI S-3400model). Field Emission Scanning Electron Microscope (FESEM) analysis was carried out by Hitachi-S 3400N model with an applied accelerating voltage of $15 \mathrm{kV}$. The cross-section of the virgin membrane and treated membrane were analyzed to conclude the fouling rate.

\subsubsection{Gas chromatography with mass spectrometer}

Gas Chromatography with Mass Spectrometer (GC-MS) analysis using GC MS5975 C Agilent was carried out for the water obtained before and after treatment to evaluate the complete eradication of pollutants after the process. Samples collected as described in section 2.2 were centrifuged, followed by thorough mixing of supernatant using ethyl acetate, and the obtained samples were collected twice-using separating funnel. The samples collected were concentrated using a rotary evaporator and subjected to GC-MS analysis; the same procedure was repeated for treated water samples. The results obtained for the mass fragmentation pattern for the raw effluent and treated water were compared with the NIST library for further interpretation.

\subsection{Phyto-Toxicity Test}

In order to evaluate the toxicity of the treated samples, Vigna radiata seeds were chosen for assessing phyto-toxicity. Proper sunlight, water, and nutrient soil are supplied. The plantation area was about $29.5 \mathrm{~cm} * 24.5 \mathrm{~cm}$, filled with alluvial soil. After the germination period of ten days, random plants were selected for examination with groundwater as control. The results of all samples were compared for phytotoxicity.

\subsection{Cyclic Voltammetry Studies}

To study the oxidation and reduction peaks of the treated as well as raw wastewater by this electrochemical technique using Electrochemical Workstation CHI 660 D, USA.

\section{Results and Discussion}

\subsection{Optimization Studies for Electro Ooxidation}

\subsubsection{Effect of Time and $\mathrm{pH}$}

The collected sample was subjected to the electro-oxidation process at the sample $\mathrm{pH}$ to optimize the time required for the degradation of organic pollutants contained in the wastewater sample. From Fig. 2(a), it is evident that the time required for removal of the organic pollutant was $120 \mathrm{~min}$, beyond the time it resulted in a constant removal rate. The major parameter that affects the electrochemical reaction is solution $\mathrm{pH}[28,29]$. In order to evaluate the stability of hydroxyl formation, the $\mathrm{pH}$ of tannery wastewater was varied between 5 and 9 using $1 \mathrm{M}\left(\mathrm{NaOH} / \mathrm{H}_{2} \mathrm{SO}_{4}\right)$ keeping constant current density at $0.2 \mathrm{~mA} / \mathrm{cm}^{2}$. The percentage of COD removal rate was found to be linearly increasing with respect to time at all three $\mathrm{pH}(5,7$, and 9), as depicted in Fig. 2(b). The $\mathrm{pH} 7$ represented the maximum percentage (85\%) of the COD removal rate compared to the other two conditions. The minimal reduction of COD at $\mathrm{pH} 5$ may be due to the evolution of hydrogen ions near the cathode material, which leads to the evolution of hydroxyl ions near the anode, which predominantly affects the COD removal. At pH 9 the COD removal is low may be due to the higher rate of production in $\mathrm{OH}$ ions, which is unstable and leads to the formation of hydroxide precipitation on the electrode. Similar reports were reported [29] for high removal efficiency at neutral $\mathrm{pH} 7$.

In the advanced oxidation process, the predominant radical is $\left(\mathrm{OH}{ }^{*}\right)$, which favors the conversion of organic pollutants to inorganic pollutants as per equations1 \& 2 . Since the lifetime of hydroxyl radical is very much shorter, it cannot accumulate on anode surface [30].

$$
\begin{gathered}
M M O+\mathrm{H}_{2} \mathrm{O} \rightarrow \operatorname{MMO}\left(\mathrm{OH}^{*}\right)+\mathrm{H}^{+}+e^{-} \\
M M O\left(\mathrm{OH}^{*}\right)+\text { organic pollutant } \rightarrow \\
\mathrm{CO}_{2}+\mathrm{H}^{+}+e^{-}+\text {Inorganic Salt }
\end{gathered}
$$

Electrochemical oxidation of aqueous solution exhibits both type of removal mechanism, however, in case of indirect oxidation formation of a strong oxidizing agent such as chlorine is likely electro-generated at the anode side as per the equations 3-7. The chlorine and hypochlorite ions produced by anodic oxidation play an important role in oxidizing organic compounds. 

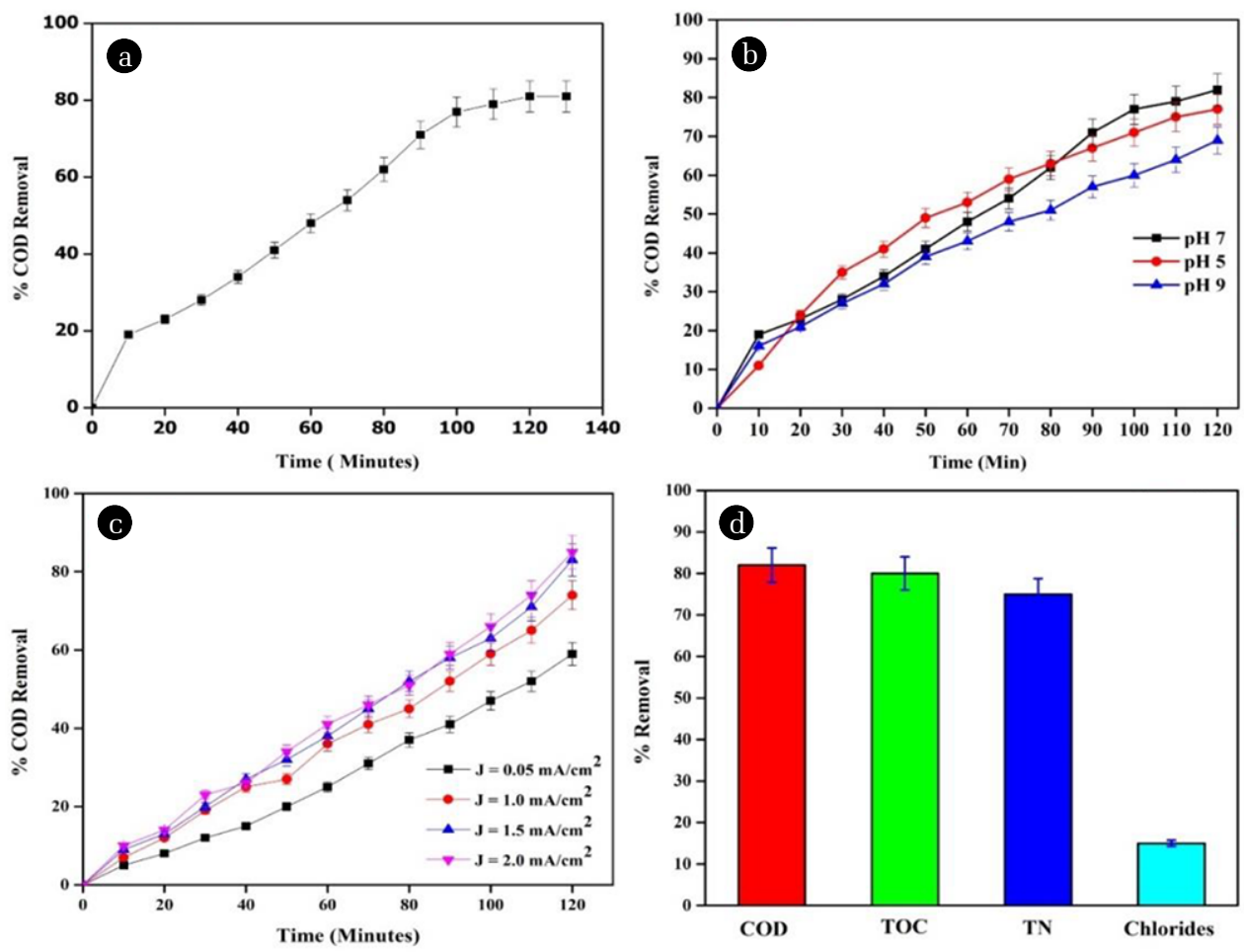

Fig. 2. (a) Effect of Time on COD removal at $\mathrm{J}=0.20 \mathrm{~mA} / \mathrm{cm}^{2}, \mathrm{pH}-7$ in batch process, Temp $=25^{\circ} \mathrm{C}$; (b) Effect of $\mathrm{pH}$ on $\mathrm{COD}$ removal at $\mathrm{J}=0.20 \mathrm{~mA} / \mathrm{cm}^{2}$ in batch process, Temp $=25^{\circ} \mathrm{C}$; (c) Effect of Current Density on COD removal at $\mathrm{pH}=7.0, \mathrm{Temp}=25^{\circ} \mathrm{C}$ in batch process, (d) Effect of percentage removal of COD, TOC, TN, Chlorides at CD $0.15 \mathrm{~mA} / \mathrm{cm}^{2} ; \mathrm{pH}=7.0$, Temp $=250 \mathrm{C}$ in batch process.

$$
\begin{gathered}
2 \mathrm{Cl}^{-} \leftrightarrow \mathrm{Cl}_{2}+2 e^{-} \\
\mathrm{Cl}^{-}+\mathrm{OH}^{*} \leftrightarrow \mathrm{ClO}^{-}+\mathrm{H}^{+}+e^{-} \\
\mathrm{ClO}^{-}+\mathrm{OH}^{*} \leftrightarrow \mathrm{ClO}_{2}{ }^{-}+\mathrm{H}^{+}+e^{-} \\
\mathrm{ClO}_{2}{ }^{-}+\mathrm{OH}^{*} \leftrightarrow \mathrm{ClO}_{3}{ }^{-}+\mathrm{H}^{+}+e^{-} \\
\mathrm{ClO}_{3}{ }^{-}+\mathrm{OH}^{*} \leftrightarrow \mathrm{ClO}_{4}{ }^{-}+\mathrm{H}^{+}+e^{-}
\end{gathered}
$$

The other reactions that may happen in the bulk solution, which takes part in the removal of organic pollutants, are represented in equation 8,9 .

$$
\begin{gathered}
\mathrm{Cl}_{2}+\mathrm{H}_{2} \mathrm{O} \rightarrow \mathrm{HOCl}+\mathrm{H}^{+}+\mathrm{Cl}^{-} \\
\mathrm{HOCl} \rightarrow \mathrm{H}^{+}+\mathrm{OCl}^{-}
\end{gathered}
$$

\subsubsection{Effect of current density}

In this work, the effect of current density was carried out at different ranges such as (0.05 to 0.2$) \mathrm{mA} / \mathrm{cm}^{2}$, and reduction in percentage COD removal was observed as shown in Fig. 2(c). The applied current density in the electrochemical degradation process induces the generation of free radicals on the electrode surface. From Fig. 2(c), it clearly shows an increase in the degradation of COD was gradual with an increase in time along with an increase in current density. This is mainly due to the production of $\mathrm{OH}^{*}$ radicals, which is directly proportional to the current density [31]. The removal rate of COD at current density $0.05 \mathrm{~mA} / \mathrm{cm}^{2}$ was low as much as when compared with other current density, which is due to oxygen evolution from $\mathrm{OH}^{*}$ radicals by electrolysis of water and some undesirable side reactions occurred in the electro-oxidation process [32]. It was remarkably found that the COD reduction rate at CD $0.15 \mathrm{~mA} / \mathrm{cm}^{2}$ was $81 \%$, which is comparatively higher than the other Current density $\left(0.05,0.1,0.2 \mathrm{~mA} / \mathrm{cm}^{2}\right)$ values. So the optimum CD was $0.15 \mathrm{~mA} / \mathrm{cm}^{2}$ because high current density will result in the generation of oxidant species and higher energy consumption [33]. The energy consumption for the electro-oxidation process was found to be $0.25 \mathrm{kWh} / \mathrm{kg}$ COD removal, which was very low when compared to previous results reported $[34,35]$. When there is an increase in current density, apparently, there is a decrease in TOC value, and these results are very much similar to the results obtained by [36]. The reduction in the organic pollutants during electrochemical treatment is mainly because of direct oxidation occurring on the anode material results in the generation of active oxygen [37, 38]. Fig. 2(d) represents the percentage removal of various parameters such as COD, Total Organic Carbon (TOC), Total Nitrogen (TN), and Chlorides for current density $0.15 \mathrm{~mA} / \mathrm{cm}^{2}$. The removal rate of COD and TOC was found to be high with a higher current density, which was found to be on par with earlier reports [34]. 


\subsection{Optimization of MBR Studies}

\subsubsection{Effect of hydraulic retention time}

One of the important parameters for membrane bioreactor is Hydraulic Retention Time (HRT) of the samples that was maintained as such in the collected form with Mixed Liquor Suspension Solids (MLSS) constant at 3,200 mg/L. The collected samples were acclimatized with the collected activated sludge before initiating the experiments. The experiments were carried out at different HRT values, and samples were collected for every one hour to optimize the time, as shown in Fig. 3(a). The COD removal was found to be gradual and maximum at $6 \mathrm{~h}$, beyond which COD removal became constant. The optimized hydraulic retention time in this experiment is comparatively low, and the percentage of COD removal was high compared with our previous reports [22].

\subsection{IEOMBR Studies}

The IEOMBR process was carried out with optimized values obtained from EO and MBR studies. Before integrating electro-oxidation with the biological treatment process, the viability of the microorganisms should be checked with the applied voltage. In the present study, the applied voltage was $0.95 \mathrm{~V} / \mathrm{cm}$, which is comparatively lesser when compared with other reported works in the range higher than $1.14 \mathrm{~V} / \mathrm{cm}$, which may affect the microbial activity [39].

\subsubsection{Biodegradable index}

Biodegradable Index (BI) was one of the major parameters in biological wastewater treatment. The ration between BOD and COD is used to calculate the biodegradable index [40]. Fig. 3(b) shows the BI. Index for treated water from EO that shows a remarkable increase in the BI. Value, which ultimately increases the activity of the activated sludge process to treat the wastewater in an efficient manner. The increase in BI. Index was mainly due to the complete mineralization of organic pollutants, which drastically reduces the bio-load to the microbial community, which may reduce biofouling. The BI. index does not decrease after $40 \mathrm{~min}$; similarly, the trend tends to increase until the end of the process. These results prove that electrochemical oxidation helps to increase the BI. Index of the treated water than any other process.

\subsubsection{Permeate flux decline}

The experiment was carried out with a constant transmembrane pressure of $141.325 \mathrm{kPa}$, MLSS concentration of 3,200 mg/L, $\mathrm{pH}$ was maintained at neutral with a CD $0.15 \mathrm{~mA} / \mathrm{cm}^{2}$. The decline in permeate flux, which is shown in Fig. 4(a), is mainly due to the accumulation of the biofilm formation and the deposition of small particles in the filtration pathway, which blocks the pores in turn increase initially osmotic pressure of the membrane [41]. The fouling rate for IEOMBR is very much less when compared to the MBR system. Previous studies were on par and exhibited $[19,20]$ a similar decrease in fouling rate in membranes was used for electrochemical integrated membrane bioreactor compared to MBR. The back-washing time for the membrane used in both MBR and IEOMBR is $60 \mathrm{~s}$. The time interval between every back-washing is $60 \mathrm{~min}$. However, the back-washing is done periodically in MBR systems, although the fouling mechanism followed by the MBR system is irreversible, which is evident from the result obtained for permeate flux decline (Fig. 4(a)) i.e., a drastic decline in the performance. The IEOMBR system, it follows the reversible fouling as shown in Fig. 4(a), the performance of the system is much better than MBR. The permeate flux was $17 \mathrm{~L} / \mathrm{m}^{2} . \mathrm{h}$ for both MBR and IEOMBR, but there was a higher rate of declining permeate flux in the MBR compared with IEOMBR. This may be due to the formation of a cake layer over the membrane, whereas on IEOMBR the deposition of bio-film and pore constriction have been reduced by integration of EO process into the bulk system. The permeate flux improvement has been found 50\% in IEOMBR, and it was found to noticeably higher to previous reports [42].

\subsubsection{Performance comparison}

The comparison of percentage COD removal is shown in Figure 4(B) for MBR and IEOMBR. From figure 4(B), it was observed that the removal rate was higher in IEOMBR than MBR. The study on IEOMBR and MBR was carried out for 30 days to check the
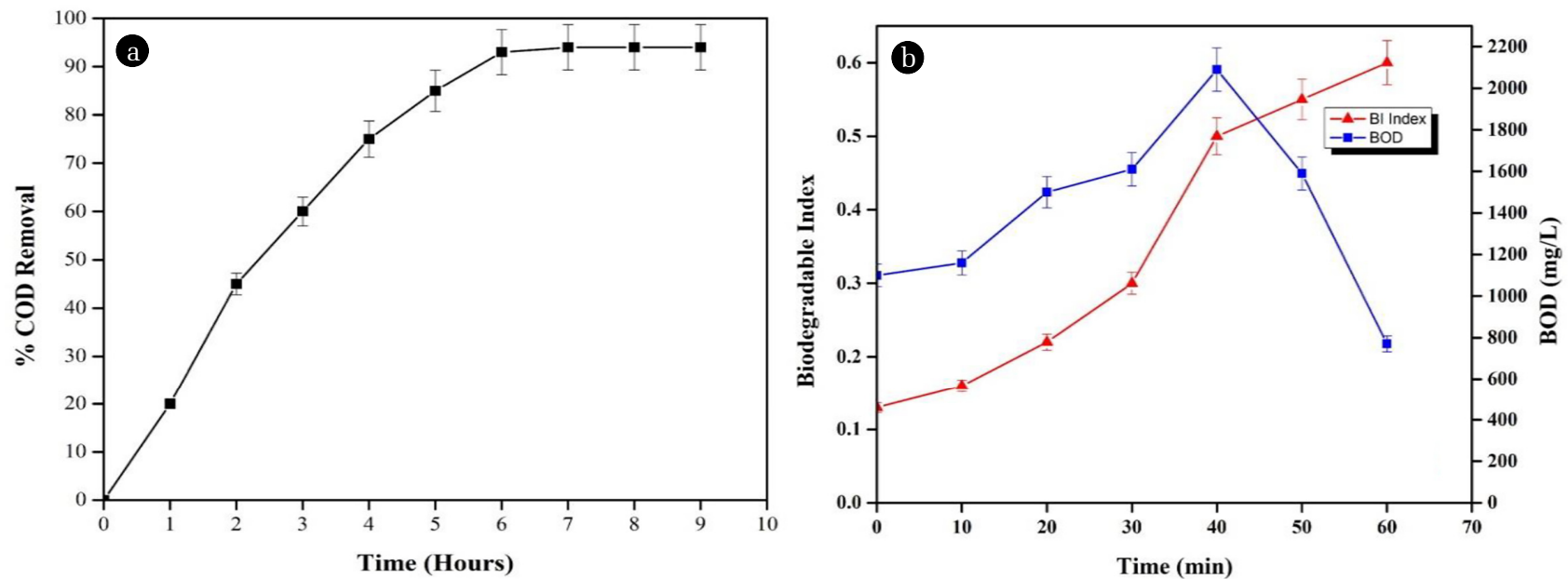

Fig. 3. (a) Effect of Hydraulic Retention Time on COD removal, MLSS concentration = 3,200 mg/L; (b) Effect of Biodegradable Index and BOD removal at $\mathrm{pH}=7.0, \mathrm{~J}=0.15 \mathrm{~mA} / \mathrm{cm}^{2}, \mathrm{MLSS}$ concentration $=3,200 \mathrm{mg} / \mathrm{L}$ in batch process. 
stability of the process and the fouling rate in the membrane. Back-washing (time-60 seconds) to the membrane was supplied at an interval time of $60 \mathrm{~min}$ during the process, and the sample was collected for a period of $6 \mathrm{~h}$. EO has reduced the sludge deposition by the IEOMBR due to the mineralization process. The percentage removal of COD, TOC, TN, and Chloride was found to be increased in IEOMBR than MBR as shown in Figure 4(C), and the results are $13 \%, 7 \%, 8 \%$, and $5 \%$ respectively, which is due to the incorporation of advanced oxidation process as a pretreatment to the microfiltration along with activated sludge process. During the process, it was noticed that there is no change in the temperature of the solution. Since the treatment efficiency is found to be superior in IEOMBR than MBR, the cost-effectiveness for the IEOMBR is very much lesser when compared with $\mathrm{MBR}$. The replacement of membrane cost is higher in MBR compared with IEOMBR due to low biofouling in IEOMBR. However, MBR and IEOMBR had equal chemical dosage for back-washing, and the pumping cost is the same for both. Similar reports from the literature [22, 23] reveal integrated electro-oxidation with membrane bioreactor exhibited a better efficiency in pollutant degradation compared with MBR. The energy consumption calculated for the MBR process was found to be $1.3 \mathrm{kWh} / \mathrm{m}^{3}$, whereas the energy consumption calculated for the IMBR process was found to be $1.32 \mathrm{kWh} / \mathrm{m}^{3}$. However, the energy consumption for the integrated system was found to be similar to that of the MBR process. The fouling rate was found to be higher in the MBR process than IMBR, which implies that the cost for replacement of membrane in MBR will be higher than the IMBR process.

\subsubsection{Cyclic voltammetry studies}

The Cyclic Voltammetry study of raw wastewater and treated water by MBR, IEOMBR, is shown in Fig. 4(d). The study was carried out using Pt as a working electrode, standard calomel electrode (SCE) as a reference electrode in $0.1 \mathrm{M} \mathrm{Na}_{2} \mathrm{SO}_{4}$ as electrolyte solution with specific volumetric parts of raw wastewater and treated water at a scan rate of $0.1 \mathrm{mv} / \mathrm{s}$. The image shows that there was some oxidation peak at $0.2 \mathrm{~V}$ and a reduction peak at $-0.3 \mathrm{~V}$, clearly representing the presence of pollutants in the raw wastewater. The oxidation peak observed in MBR effluent at $0.2 \mathrm{~V}$ proves that the pollutant has not been completely removed by MBR, some negligible amount of trace elements have been present in the treated water. The compound for oxidation \& reduction peak at $0.2 \mathrm{~V}$
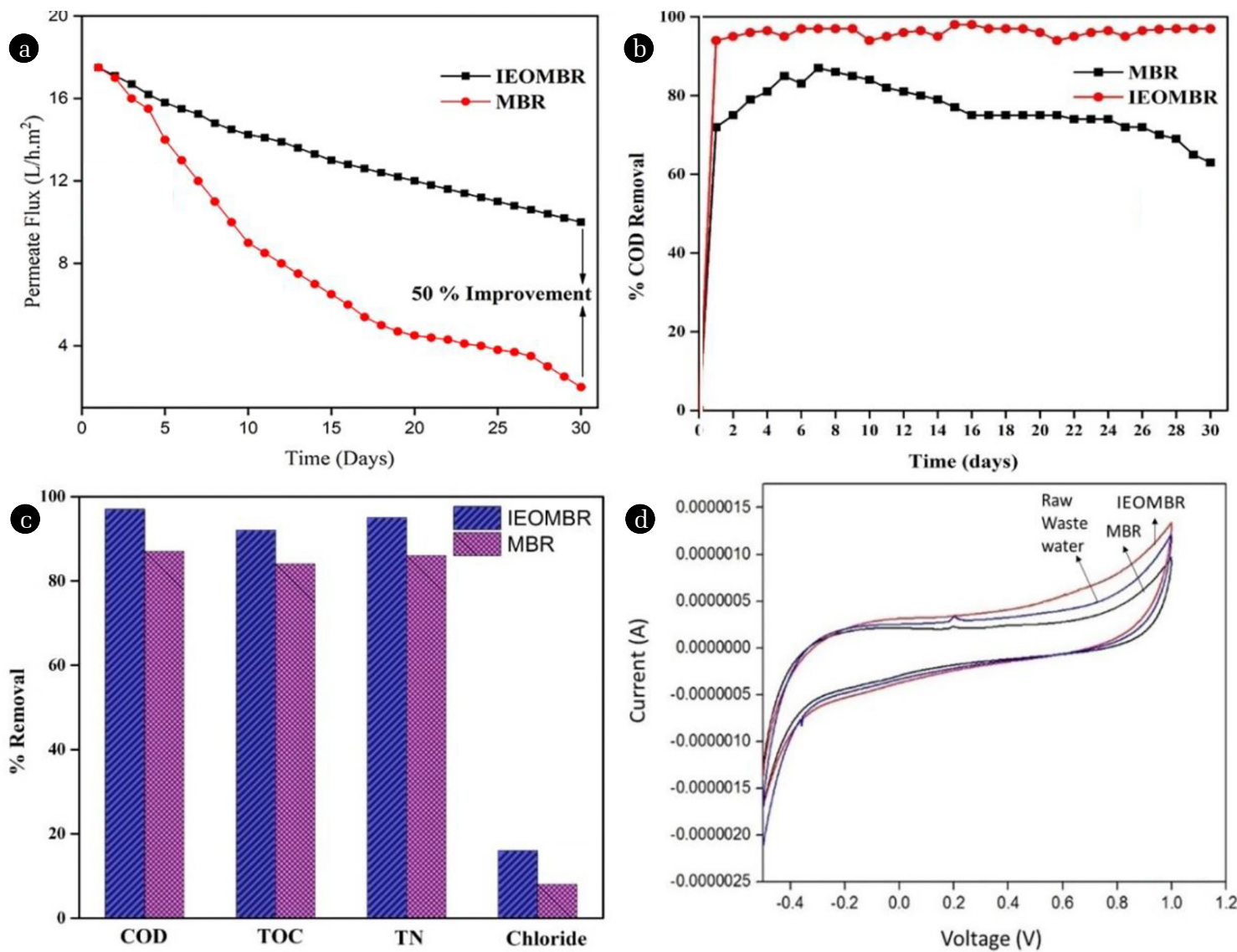

Fig. 4. (a) Effect of MBR and IEOMBR on Permeate flux, $\mathrm{pH}=7.0, \mathrm{~J}=0.15 \mathrm{~mA} / \mathrm{cm}^{2}, \mathrm{MLSS}$ concentration $=3,200 \mathrm{mg} / \mathrm{L}$ in continuous process for 30 days; (b) Performance comparison of MBR with IEOMBR J = $0.15 \mathrm{~mA} / \mathrm{cm} 2$; pH 7; MLSS = 3,200 mg/L; back wash time 60 Seconds; (c) Performance comparison of MBR with IEOMBR for various parameters for a period of 30 days; (d) Cyclic Voltammetry analysis for raw wastewater, MBR, IEOMBR treated water using Pt working electrode; SCE as reference electrode; $\mathrm{pH}=7$, at a scan rate of $0.1 \mathrm{mV} / \mathrm{s}$. 
\& $-0.3 \mathrm{~V}$ might be due to chlorine present in methylene chloride of treated effluent by MBR. Nevertheless, IEOMBR treated effluent shows no oxidation peak and reduction peak, evident that the pollutant has been completely removed in the IEOMBR process and confirms the previous results.

\subsubsection{Scanning electron microscope}

SEM images of surface (Fig. S1) and a cross-sectional view of the pure membrane is shown in Fig. 5(a), which clearly depicts the micro-level pores present in the membrane. The pores are evenly distributed and arranged in a unique way all over the membrane, which gives a clear pathway for a better filtration rate. Fig. 5(b) shows the cross-section of the membrane used after MBR. The image evidently shows the accumulation of the biofilm over the membrane, which hinders the pores of the membrane in such a way that it slows down the filtration process and reduces the life of the membrane. Even though the formation of bio-film enhances the activity of the microbes, it is a major disadvantage in a membrane process, which depletes the porosity and increases the capital cost. So a back-wash was induced in the membrane process for irreversible fouling. The Cross-sectional view of the membrane is shown in Fig. 5(c) used in IEOMBR, which shows the formation of a gel layer over the membrane façade is very less when compared to the MBR process. The pore-blocking leads to the depletion in membrane porosity [43]. The membrane used in the $\mathrm{EOMBR}$ resembles the pristine membrane, which proves that the pore block due to the biofilm activity has been eventually reduced. The obtained results confirm the analytical results that IEOMBR is superior and has evidently reduced biofouling.

\subsubsection{Gas chromatography with Mass Spectroscopy Study}

Gas chromatography with Mass Spectroscopy was carried out for raw effluent (Fig. 6(a)) and the treated water from IEOMBR (Fig. 6(b)). It was clearly found in Fig. 6(a) that there was the presence of some organic compounds at a retention time of 10.286 min with peak area $=26236099$. From the mass spectrum, it was found that methylene chloride, molecular weight $=84.93 \mathrm{~g} / \mathrm{mol}$ was ob-
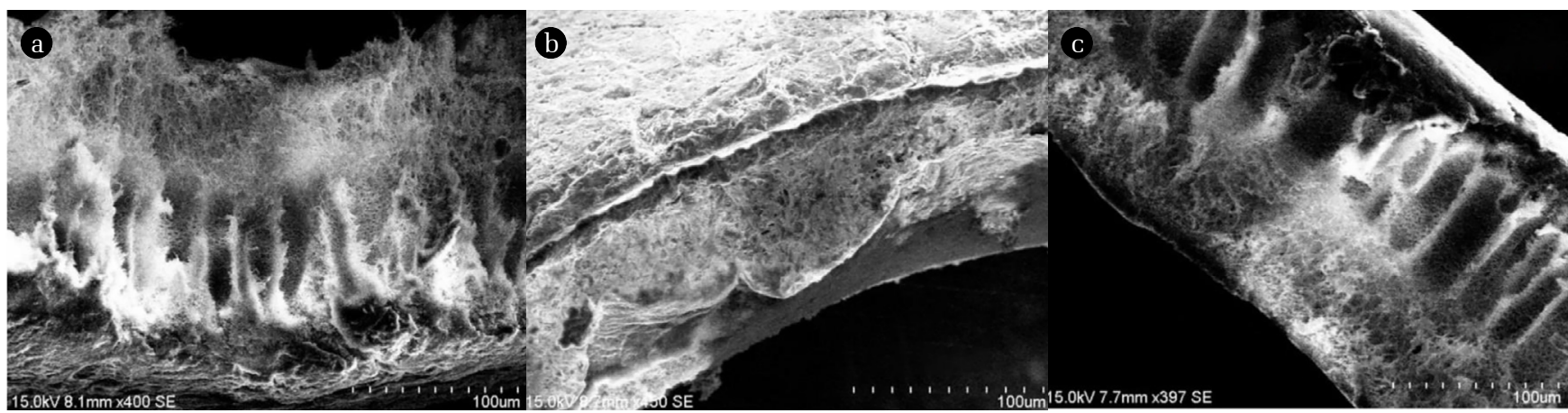

Fig. 5. FESEM images of (a) pure membrane; (b) MBR membrane; (c) IEOMBR membrane.

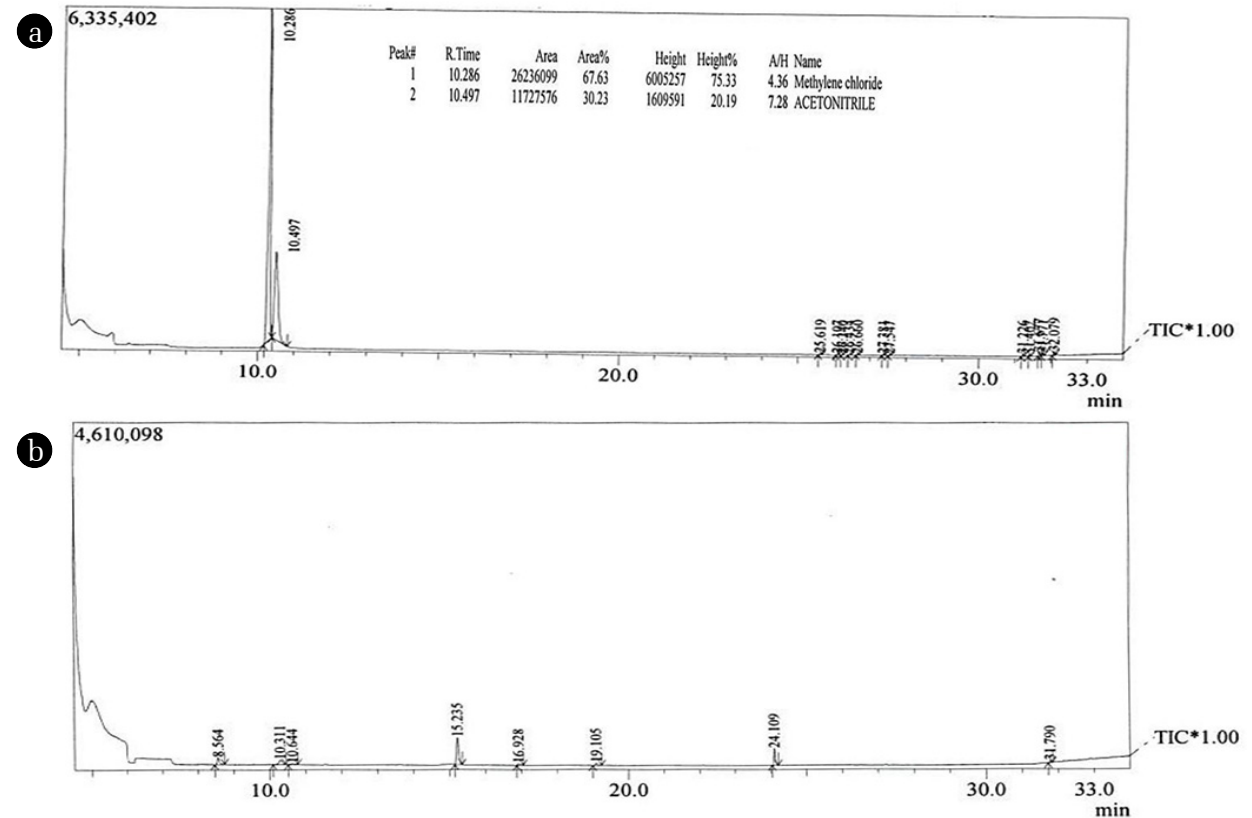

Fig. 6. (a) Gas Chromatography with mass spectroscopy analysis for Raw Tannery wastewater; (b) Gas Chromatography with mass spectroscopy for treated water from IEOMBR. 


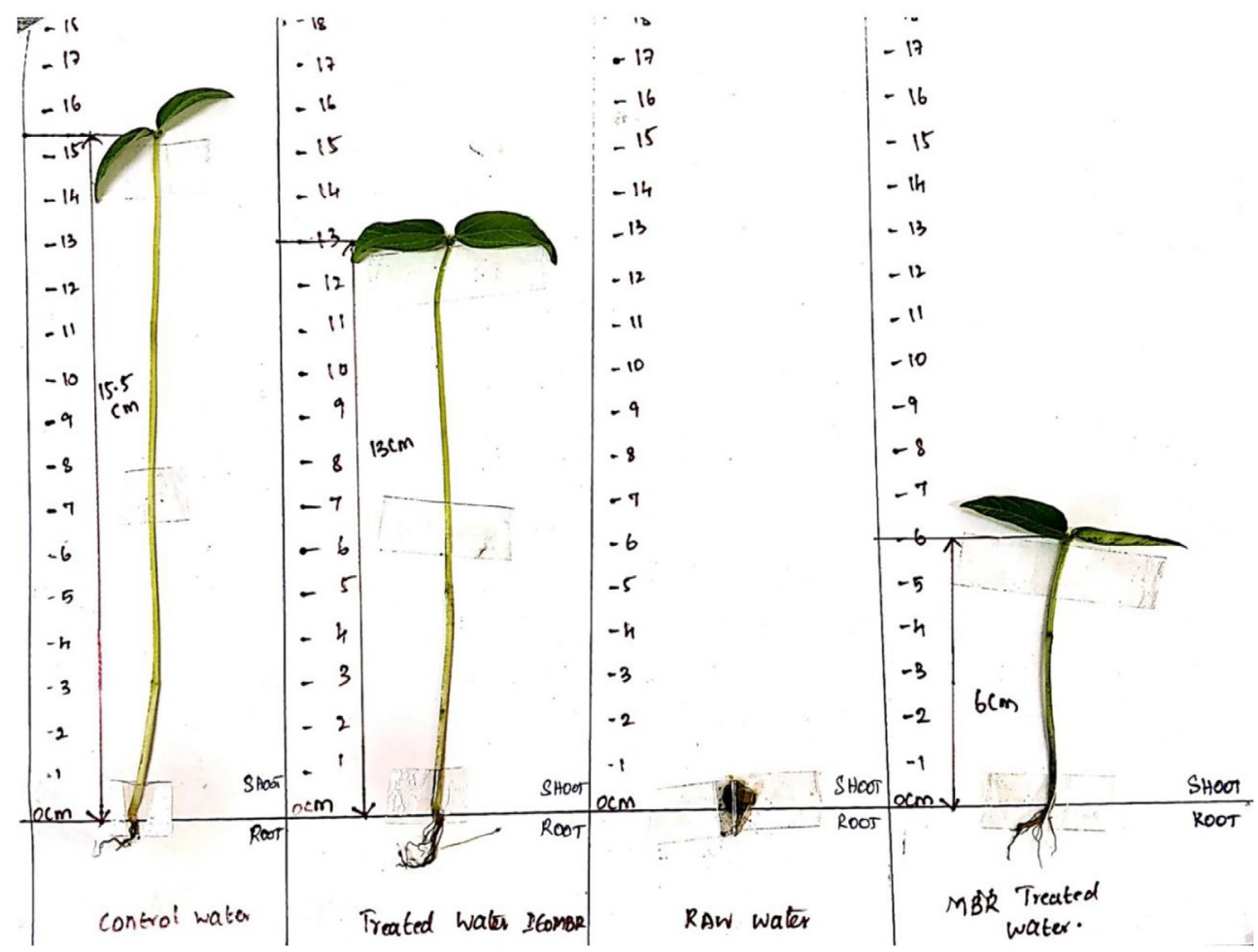

Fig. 7. Phyto-toxicity test using Vigna radiate for Treated water from IEOMBR, MBR, Raw tannery wastewater.

served as well. Methylene chloride has a widespread application in the chemical industry, such as metal degreasing, solvent for extraction and chemical synthesis, etc. Long exposure to methylene chloride causes CNS depression and gastrointestinal irritation. When it is contacted with skin, it leads to irritation of skin \& eye irritation with body burns. The peak at 10.497 in GC corresponds to the acetonitrile group. Acetonitrile is mainly used for the extraction of fatty acids from animal fats and skins. Acetonitrile has very bad effects over humans at a higher level, whereas in the present study, the reported value was very low when compared to methylene chloride. In electrochemical oxidation, the process completely mineralizes organic completed, thereby eradicating methylene chloride. However, MBR systems mainly depend on the activity of the activated sludge process. Hence, in MBR, it is very hard for the microorganism's digestive system to remove the toxic methylene chloride. The low performance of membrane bioreactor compared to the IEOMBR (Integrated Electro-oxidation Membrane Bioreactor) was due to the same. Consequently, the results obtained for treated water from IEOMBR clearly shows that there was no presence of methylene chloride and in par with other observations.

\subsubsection{Phyto-toxicity test}

Phyto-toxicity tests were carried out for the treated water from both IEOMBR and MBR to check the viability of water for plant growth. Vigna radiate seeds were irrigated twice a day for seed germination tests with groundwater for toxicity studies. The results in Fig. 7 shows that the control water yielded a plant growth up to $15.5 \mathrm{~cm}$, treated water from MBR showed a growth of up to
$6 \mathrm{~cm}$, and treated water from IEOMBR shows growth of up to $13 \mathrm{~cm}$ for ten days under optimized growth condition. The seeds grown using raw water did not show any significant growth with both fungal and bacterial contamination, which may be attributed to the inadequacy of the raw water to initiate the growth compared to treated water. The improper growth activity in the MBR treated water is mainly due to the lack of pretreatment, whereas in IEOMBR treated water, the growth was highly appreciable and comparable with that of groundwater. Earlier reports [22] reveal a similar pattern in toxicity study where treated water obtained from the integrated combination (MBR-EO) were subjected for toxicity test with Daphnia Magna, which does not affect the growth of organisms. Both raw tannery wastewater and MBR effluent contain contaminants that affect seed germination, which is the first stage of plant development. This may significantly affect the plants to survive and compete in the environment. Hence, the treated water had a higher growth rate than the raw tannery wastewater and MBR effluent [44, 45]. These results are an indication that the integration of the electro-oxidation process with membrane bioreactor shall produce a better treatment option, which was evident from other obtained analysis discussed.

\section{Conclusions}

The integration of electrochemical oxidation with membrane bioreactor exhibits a better performance with an effective percentage removal of COD, TOC, Total Nitrogen, and Chlorides such as $97 \%$, $90 \%, 94 \%$, and $71 \%$ respectively. FESEM images of the membrane 
used in the IEOMBR illustrated that the reduction in biofouling compared to the MBR process. The results obtained from the GC-MS, toxicity tests also prove that IEOMBR shows a complete mineralization process and thus an integrated process ensures the viability of pilot plant study and eco-friendly to the process plant. Hence, the above results are a path to accept that the electro-oxidation as pretreatment for the MBR process resulting in reduced biofouling.

\section{Acknowledgment}

The authors acknowledge the financial support given by the Department of Science and Technology (DST), India, vide letter numbers DST/TM/WTI/2K12/65(G), dt: 26.06.2013 and DST/INT/ Korea/P-47, dt: 18.05.2018.

\section{Author Contributions}

K.V. (Ph.D. Student) made substantial contributions to the design of the work, acquisition of data from analysis interpretation of data for the work and drafting the work for important intellectual content. K.P. (Ph.D. Student) contributed to the design of the work and interpretation of data for the work. S.S.S. (Ph.D. Student) involved in interpretation of work and drafting of work for important intellectual content. N.J. (Ph.D. Student) carried analysis and drafting of work. M.P. (Ph.D. Student) contributed on the design of experiments and analysis, interpretation of work. K. N. (Assistant Professor) involved in acquisition of data and interpretation. Y.S.H. (Professor), N.B.S. (Professor) were involved in final approval of the version to be published; and agreement to be accountable for all aspects of the work in ensuring that questions related to the accuracy or integrity of any part of the work are appropriately investigated and resolved.

\section{References}

1. Chai H, Li L, Wei Y, et al. Optimization of membrane fouling process for mustard tuber wastewater treatment in an anoxic-oxic biofilm-membrane bioreactor. Environ. Eng. Res. 2016;21(2):196-202.

2. Visvanathan C, Aim RB, Parameshwaran K. Membrane Separation Bioreactors for Wastewater Treatment. Crit. Rev. Env. Sci. Tec. 2000;30:1-48.

3. Barrera-Díaz C, Cañizares P, Fernández FJ, Natividad R, Rodrigo MA. Electrochemical Advanced Oxidation Processes: An Overview of the Current Applications to Actual Industrial Effluents. J. Mex. Chem. Soc. 2014;58:256-275.

4. ABDEL-KADER AM. A review of Membrane Bioreactor (MBR) Technology and their Applications in the Wastewater Treatment Systems. In: Eleventh International Water Technology Conference, IWTC11 Sharm El-Sheikh, Egypt. 2007. p. 269-278.

5. Santos A, Ma W, Judd SJ. Membrane bioreactors: Two decades of research and implementation. Desalination 2011;273: 148-154.
6. Bui XT, Chen SS, Nguyen PD, Nguyen TT, Nguyen TB. Hospital wastewater treatment by sponge membrane bioreactor coupled with ozonation process. Chemosphere 2019;230:377-83.

7. Fazal S, Zhang B, Zhong Z, Gao L, Lu X. Membrane separation technology on pharmaceutical wastewater by using MBR (Membrane Bioreactor). J. Environ. Prot. 2015;6(04):299.

8. Nguyen TT, Bui XT, Dang BT, Ngo HH, Jahng D, Fujioka T, Chen SS, Dinh QT, Nguyen CN. Effect of ciprofloxacin dosages on the performance of sponge membrane bioreactor treating hospital wastewater. Bioresour. Technol. 2019;273:573-80.

9. Judd S. The status of membrane bioreactor technology. Trends. Biotechnol. 2008;26:109-116.

10. Holler S. Trösch W Treatment of urban wastewater in a membrane bioreactor at high organic loading rates. J. Biotechnol. 2001;92:95-101.

11. Le-Clech P, Chen V, Fane TAG. Fouling in membrane bioreactors used in wastewater treatment. J. Membrane. Sci. 2006;284:17-53.

12. Lim AL, Bai R. Membrane fouling and cleaning in microfiltration of activated sludge wastewater. J. Membrane. Sci. 2003;216: 279-290.

13. Hong H, Zhang M, He Y, Chen J, Lin H. Fouling mechanisms of gel layer in a submerged membrane bioreactor. Bioresour. Technol. 2014;166:295-302.

14. Mousa HA, Al-Hitmi SA. Treatability of wastewater and membrane fouling. Desalination. 2007;217:65-73.

15. Tetteh EK, Naidoo DB, Rathilal S. Optimization of photo-catalytic degradation of oil refinery wastewater using Box-Behnken design. Environ. Eng. Res. 2019;24(4):711-717.

16. Shokrollahzadeh S, Abassi M, Ranjbar M. A new nano-ZnO/perlite as an efficient catalyst for catalytic ozonation of azo dye. Environ. Eng. Res. 2018;24(3):513-520.

17. Mohan N, Balasubramanian N, Basha CA. Electrochemical oxidation of textile wastewater and its reuse. J. Hazard. Mater. 2007;147:644-651.

18. Zhang J, Satti A, Chen X, Xiao K, Sun J, Yan X, Liang P, Zhang $\mathrm{X}$, Huang X. Low-voltage electric field applied into MBR for fouling suppression: performance and mechanisms. Chem. Eng. J. 2015;273:223-230.

19. Borea L, Naddeo V, Belgiorno V. Application of electrochemical processes to membrane bioreactors for improving nutrient removal and fouling control. Environ. Sci. Pollut. R 2017;24(1): 321-333.

20. Khalid Bani-Melhem, Maria Elektorowicz. Development of a Novel Submerged Membrane Electro-Bioreactor (SMEBR): Performance for Fouling Reduction. Environ. Sci. Technol. 2010;44(9):3298-3304.

21. Ibeid S, Elektorowicz M, Oleszkiewicz JA. Novel electrokinetic approach reduces membrane fouling. Water Res. 2013;47(16): 6358-6366.

22. Ouarda Y, Tiwari B, Azaïs A, et al. Synthetic hospital wastewater treatment by coupling submerged membrane bioreactor and electrochemical advanced oxidation process: Kinetic study and toxicity assessment. Chemosphere 2018;193:160-169.

23. García-Gómez C, Drogui P, Seyhi B, et al. Combined membrane bioreactor and electrochemical oxidation using $\mathrm{Ti} / \mathrm{PbO} 2$ anode for the removal of carbamazepine. J. Taiwan. Inst. Chem. E. 2016;64:211-219. 
24. Ibeid S, Elektorowicz M, Oleszkiewicz JA. Electro-conditioning of activated sludge in a membrane electro-bioreactor for improved dewatering and reduced membrane fouling. $J$. Membrane. Sci. 2015;494:136-42.

25. Qi C, Wang J, Lin Y. New insight into influence of mechanical stirring on membrane fouling of membrane bioreactor: mixed liquor properties and hydrodynamic conditions. Bioresour. Technol. 2016;211:654-63.

26. Giwa A, Dindi A, Kujawa J. Membrane bioreactors and electrochemical processes for treatment of wastewaters containing heavy metal ions, organics, micropollutants and dyes: Recent developments. J. Hazard. Mater. 2019;370:172-95.

27. American Public Health A, American Water Works A, Water Environment F Standard methods for the examination of water and wastewater. APHA-AWWA-WEF, Washington, DC;1998.

28. Chen G. Electrochemical technologies in wastewater treatment. Sep. Purif. Technol. 2004;38:11-41.

29. Gerek EE, Yılmaz S, Koparal AS, Gerek ÖN. Combined energy and removal efficiency of electrochemical wastewater treatment for leather industry. J. Water Process. Eng. 2019;30:100382.

30. Dirany A, Sirés I, Oturan N, Özcan A, Oturan MA. Electrochemical treatment of the antibiotic sulfachloropyridazine: Kinetics, reaction pathways, and toxicity evolution. Environ. Sci. Technol. 2012;46:4074-4082.

31. Zhong C, Wei K, Han W, Wang L, Sun X, Li J. Electrochemical degradation of tricyclazole in aqueous solution using $\mathrm{Ti} / \mathrm{SnO} 2$ $\mathrm{Sb} / \mathrm{PbO} 2$ anode. J. Electroanal. Chem. 2013;705:68-74.

32. Song S, Fan J, He Z, et al. Electrochemical degradation of azo dye CI. Reactive Red 195 by anodic oxidation on Ti/SnO2$\mathrm{Sb} / \mathrm{PbO} 2$ electrodes. Electrochim. Acta. 2010;55:3606-3613.

33. Ma H, Wang B, Luo X. Studies on degradation of Methyl Orange wastewater by combined electrochemical process. J. Hazard. Mater. 2007;149:492-498.

34. Silva SW, Venzke CD, Welter JB, et al. Electrooxidation using $\mathrm{Nb} / \mathrm{BDD}$ as post-treatment of a reverse osmosis concentrate in the petrochemical industry. Int. J. Env. Res. Pub. He. 2019;16(5): 816.

35. Fockedey E, Van Lierde A. Coupling of anodic and cathodic reactions for phenol electro-oxidation using three-dimensional electrodes. Water Res. 2002;36(16):4169-4175.

36. López-Grimau V, Gutiérrez MC. Decolourisation of simulated reactive dyebath effluents by electrochemical oxidation assisted by UV light. Chemosphere. 2006;62:106-112.

37. Chen X, Chen G, Yue PL. Anodic oxidation of dyes at novel Ti/B-diamond electrodes. Chem. Eng. Sci. 2003;58:995-1001.

38. Comninellis C. Electrocatalysis in the electrochemical conversion/combustion of organic pollutants for waste water treatment. Electrochim. Acta. 1994;39:1857-1862.

39. Alshawabkeh AN, Shen Y, Maillacheruvu KY. Effect of DC electric fields on COD in aerobic mixed sludge processes. Environ. Eng. Sci. 2004;21(3):321-329.

40. Abdalla KZ, Hammam G. Correlation between biochemical oxygen demand and chemical oxygen demand for various wastewater treatment plants in Egypt to obtain the biodegradability indices. Int. J. Sci.: Basic Appl. 2014;13(1):42-48.

41. Aouni A, Fersi C, Ben Sik Ali M, Dhahbi M. Treatment of textile wastewater by a hybrid electrocoagulation/nanofiltration process. J. Hazard. Mater. 2009;168:868-874.

42. Keerthi, Suganthi V, Mahalakshmi M, Balasubramanian N. Development of hybrid membrane bioreactor for tannery effluent treatment. Desalination 2013;309:231-236.

43. Wang S, Liu C, Li Q. Fouling of microfiltration membranes by organic polymer coagulants and flocculants: Controlling factors and mechanisms. Water. Res. 2011;45:357-365.

44. Calheiros CS, Rangel AO, Castro PM. The effects of tannery wastewater on the development of different plant species and chromium accumulation in Phragmites australis. Arch. Environ. Contam. Toxicol. 2008;55(3):404-414.

45. Wang W. Toxicity assessment of pretreated industrial wastewaters using higher plants. Res. J. Water Pollut. C. 1990:853-860. 